This item was submitted to Loughborough's Research Repository by the author.

Items in Figshare are protected by copyright, with all rights reserved, unless otherwise indicated.

\title{
Eating disorder symptoms and parenting styles
}

PLEASE CITE THE PUBLISHED VERSION

http://dx.doi.org/10.1016/j.appet.2009.11.009

PUBLISHER

(c) Elsevier

VERSION

AM (Accepted Manuscript)

LICENCE

CC BY-NC-ND 4.0

REPOSITORY RECORD

Haycraft, Emma, and Jacqueline Blissett. 2019. "Eating Disorder Symptoms and Parenting Styles". figshare. https://hdl.handle.net/2134/11245. 
This item was submitted to Loughborough's Institutional Repository (https://dspace.lboro.ac.uk/) by the author and is made available under the following Creative Commons Licence conditions.

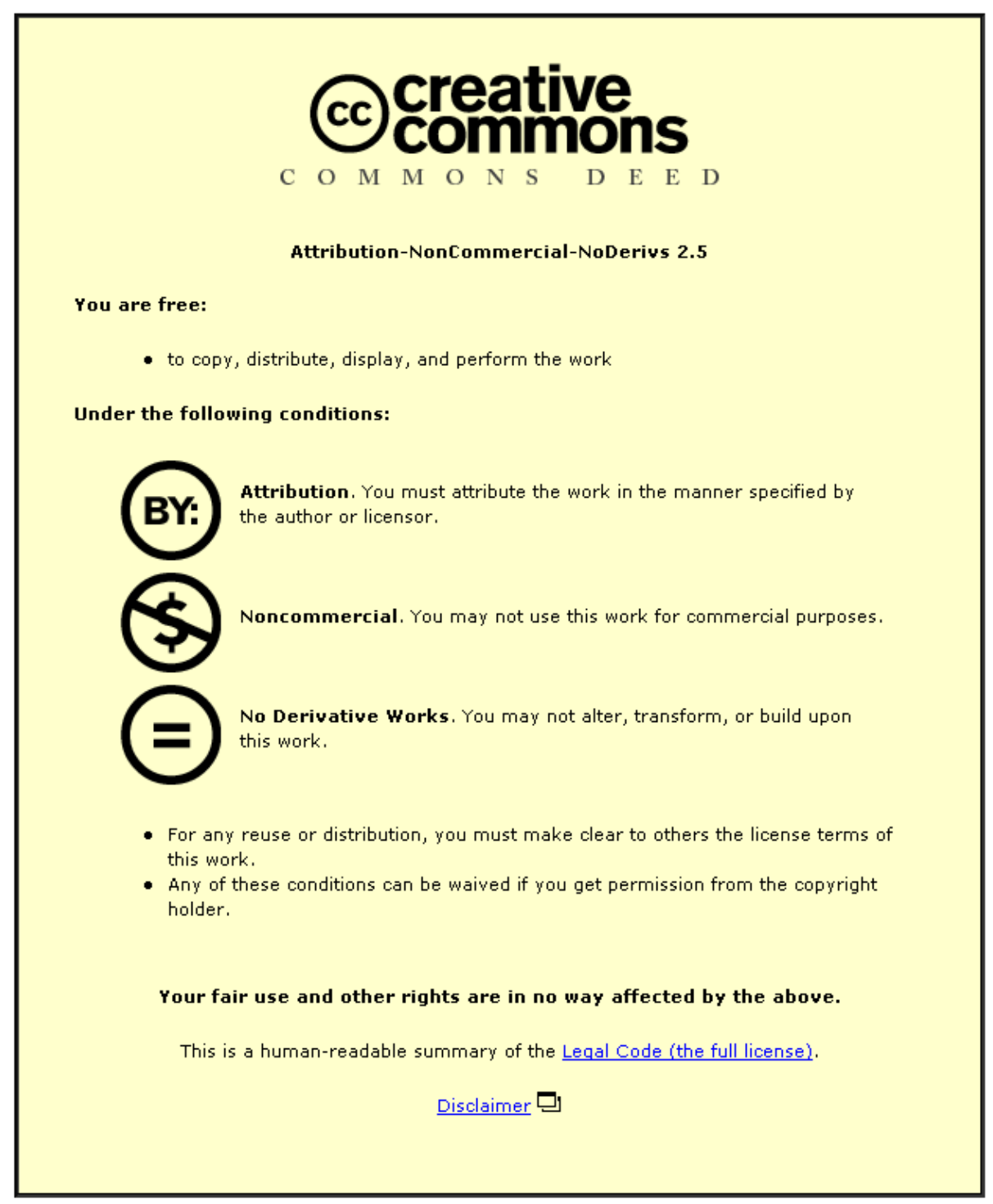

For the full text of this licence, please go to: http://creativecommons.org/licenses/by-nc-nd/2.5/ 


\title{
EATING DISORDER SYMPTOMS AND PARENTING STYLES
}

\author{
Emma Haycraft, PhD. ${ }^{\mathrm{a}}$ \\ Jackie Blissett, PhD., C.Psychol. ${ }^{\mathrm{b}}$
}

${ }^{a}$ Loughborough University Centre for Research into Eating Disorders, School of Sport, Exercise and Health Sciences, Loughborough University, Leicestershire, LE11 3TU, UK

${ }^{\mathrm{b}}$ School of Psychology, University of Birmingham, Edgbaston, Birmingham, B15 2TT, UK.

Address correspondence to Dr. Emma Haycraft, at the above address.

Email: E.Haycraft@lboro.ac.uk

Not for publication: Telephone: +44 (0)1509 228160; Fax: +44 (0)1509 223940 .

RUNNING HEAD: EATING DISORDERS AND PARENTING STYLES 


\begin{abstract}
This study aimed to examine associations between symptoms of eating disorders and parenting style, in a non-clinical sample. One hundred and five mothers completed self-report measures of eating disorder symptoms and parenting style. Higher levels of eating disorder symptoms were associated with more authoritarian and permissive parenting styles. Authoritative parenting was not significantly related to eating disorder symptoms. The findings demonstrate that eating disorder symptoms in non-clinical individuals are related to less adaptive parenting styles. These findings have potential implications for clinicians working with mothers with eating disorders.
\end{abstract}

Key words: authoritarian; eating disorders; mothers; parenting style; permissive 


\section{EATING DISORDER SYMPTOMS AND PARENTING STYLES}

For parents with eating disorders, preoccupation with their own body shape, a fear of fatness and a chaotic eating style may all adversely affect their ability to care for and nurture their child (McNicholas, 1996) and, indeed, eating psychopathology has been related to serious parenting difficulties (Woodside \& Shekter-Wolfson, 1990). Research has shown that mothers with eating disorder symptoms may implement greater control in their feeding interactions with their children, in both clinical groups (e.g., Stein, Woolley, Cooper \& Fairburn, 1994) and non-clinical parent samples (e.g., Tiggemann \& Lowes, 2002). Mothers with eating pathology have also been shown to withdraw from the feeding situation (Waugh \& Bulik, 1999). While the feeding practices of mothers displaying eating disorder symptoms have been studied, the general parenting practices of individuals with eating disorder symptoms have received little research attention (Mazzeo, Zucker, Gerke, Mitchell \& Bulik, 2005).

Many studies classify parenting into three different styles, each characterised by varying degrees of parental warmth and control (e.g., Baumrind, 1971; Darling \& Steinberg, 1993). Authoritative parents impose clear demands alongside emotional responsiveness, autonomy granting and warmth. Authoritarian parents are typified by being overly controlling and demanding and are often emotionally unresponsive. Permissive parents tend to impose little control and may be neglectful or overly indulgent. Previous research has suggested that an authoritative parenting style may facilitate optimal child development, while authoritarian and permissive parenting have been associated with less than optimal outcomes (Baumrind, 1971; Darling \& Steinberg, 1993). Less responsive parenting has been found to be associated with maternal eating disorder psychopathology (Lai \& Tang, 2008; Stein, Woolley \& McPherson, 1999). Mothers with eating disorders have been found to be more 
intrusive and verbally controlling during both mealtime and play interactions with their infants (Stein et al., 1994; Stein et al., 2001). These findings accord with the notion that the need for control is a central feature of eating pathology. Given that previous work has identified that mothers with eating psychopathology may engage in controlling interactions with their children (Stein et al., 1994; Stein et al., 2001), it is likely that this need for control may extend to their general parenting style, and that an authoritarian parenting style may be commonly seen in these women. However, some mothers with eating disorder symptoms may avoid conflict by withdrawing themselves from stressful eating interactions with their children (Waugh \& Bulik, 1999). If we extrapolate this withdrawal from conflicts over eating to other areas of parenting, we may therefore also expect to see mothers with more eating disorder symptoms exhibiting higher rates of permissive, withdrawn or neglectful parenting styles in general.

Clinical work has found mothers with eating disorders to show concerns about general parenting (Bryant-Waugh, Turner, East \& Gamble, 2007a; Bryant-Waugh, Turner, Jones \& Gamble, 2007b) and, indeed, general parenting interventions are recommended for women with eating disorders who are also mothers (Bryant-Waugh et al., 2007a; 2007b). The little research which has considered the parenting styles of those with eating psychopathology found no significant differences in the parenting styles of mothers with and without eating disorders (Agras, Hammer \& McNicholas, 1999). However, no research to date has examined which particular styles of parenting may be implemented by those displaying eating disorder symptoms in a non-clinical parent sample.

The current study aimed to examine whether symptoms of eating disorders are related to less than optimal parenting styles. It was predicted that higher levels of reported eating disorder symptoms would be related to less adaptive parenting styles (i.e. more authoritarian or more permissive). It was also predicted that lower levels of eating disorder symptoms would be associated with a more authoritative parenting style. 
Method

\section{Participants}

One hundred and five mothers were recruited via nursery schools and preschools in England. The mothers had a mean age of 35 years $(S D 4.65)$ and the mean child age was 39 months ( $S D$ 11.67). Respondents had a mean of five years of education after age 16 (SD 3.11). They were predominantly (75\%) in "managerial and professional occupations", as classified by the National Statistics Socio-Economic Classification; self-coded method (Office for National Statistics, 2005). Ethnicity data were not collected but the nurseries and preschools served predominantly white neighbourhoods. Respondents were excluded if they failed to complete all of the questionnaire measures (with the exception of child height and weight).

\section{Measures and procedure}

Following institutional review board ethical approval and informed consent, mothers completed the following self-report questionnaires and returned them to the researcher using a postage-paid envelope. Mothers also reported their own and their child's heights and weights. These were converted into Body Mass Index (BMI) scores $\left(\mathrm{kg} / \mathrm{m}^{2}\right)$ for mothers and BMI Zscores for children, using the Child Growth Foundation Reference Curves Disc which standardises BMI for age and gender (Child Growth Foundation, 1996). As some mothers did not report their child's height and/or weight, BMI Z-scores were only able to be calculated for just over half of the sample of children $(n=56)$.

Eating Disorder Inventory-2 (EDI-2; Garner, 1991): The EDI-2 is a self-report measure of symptoms of eating disorders. The three eating-related subscales were administered for this study: Drive for thinness; Bulimia; and Body dissatisfaction. Response options range from 
'always' to 'never' and higher scores reflect greater levels of eating pathology. The EDI-2 has been used extensively with non-clinical samples (e.g., Berman, Lam \& Goldner, 1993; Blissett, Meyer \& Haycraft, 2006) and has demonstrated good levels of reliability and validity (Garner, 1991). In the current sample, Cronbach's alpha coefficients were: .85 for Drive for thinness; .61 for Bulimia; and .93 for Body dissatisfaction, indicating reasonable reliability.

Parenting Styles and Dimensions Questionnaire (PSDQ; Robinson, Mandleco, Olsen \& Hart, 2001): The PSDQ assesses how often parents exhibit particular behaviours towards their child. Thirty-two items comprise three subscales: Authoritative (measuring parental warmth, reasoning and autonomy granting); Authoritarian (measuring coercive, hostile and punitive practices); and Permissive (measuring parental inconsistency and indulgence). Prior to distribution of the questionnaire, four 'physical coercion' questions contributing to the Authoritarian subscale were removed due to insufficient provision for dealing with reports of child abuse or corporal punishment. Adequate levels of reliability and validity have previously been found for the PSDQ (Robinson et al., 2001) and Cronbach's alpha coefficients from the current sample indicated acceptable reliability: .83 for Authoritative; .69 for Authoritarian; and .65 for Permissive subscales.

\section{Data analysis}

Descriptive statistics were calculated and then a series of Pearson's correlations were computed, followed by three regressions (see below).

\section{Results}

The mean scores for the EDI-2 subscales (Drive for thinness: mean 3.33, SD 4.62; Bulimia: mean 1.00, SD 1.97; Body dissatisfaction: mean 10.65, SD 8.58) are in line with results from other studies of non-clinical samples (e.g., Blissett et al., 2006). The mean scores 
for the PSDQ (Authoritative: mean 4.11, SD 0.47; Authoritarian: mean 1.56, SD 0.44; Permissive: 1.94, $S D$ 0.61) are also in line with results from previous investigations with samples of mothers (e.g., Blissett \& Haycraft, 2008). Mothers' mean BMI was 24 (SD 4.49) and children's mean BMI Z-score was 0.39 (SD 1.89), both of which indicate 'healthy' weight.

Pearson's correlations (Table 1) were carried out to examine associations between eating disorder symptoms, parenting style and maternal and child BMI.

\section{---TABLE I ABOUT HERE---}

Eating disorder symptoms were not significantly related to authoritative parenting. Drive for thinness and bulimia were positively associated with authoritarian parenting while higher levels of drive for thinness and body dissatisfaction were significantly related to a more permissive parenting style. Children's BMI Z-scores were unrelated to any EDI-2 or PSDQ variables. Maternal BMI was positively and significantly associated with all three EDI-2 subscales but was not related to parenting styles. The three EDI-2 subscales were all significantly and positively associated with each other. Authoritative parenting was negatively related to authoritarian and permissive parenting and an authoritarian style was positively associated with permissive parenting.

Pearson's correlations also revealed that child age was negatively related to authoritative parenting $(\mathrm{r}-.246, \mathrm{p}<.05)$ and positively related to authoritarian parenting $(\mathrm{r}$ $.334, \mathrm{p}<.01$ ) but it was not significantly related to permissive parenting or to the EDI-2 subscales. 
In order to identify whether eating disorder symptoms were still significantly related to authoritarian or permissive parenting after controlling for child age and maternal BMI, a series of regression analyses were subsequently conducted controlling for these covariates. A composite EDI-2 score was created, by summing responses to Drive for thinness, Bulimia and Body dissatisfaction, given the strong inter-relationships between the three EDI-2 subscales. Child age and maternal BMI were entered in Step 1 and the EDI-2 total score was created and entered in Step 2. Regressions were conducted separately for each of the three parenting styles.

\section{---TABLE II ABOUT HERE---}

Authoritative parenting style was significantly predicted only by children's age in Steps 1 and 2. Mothers were more authoritative when their children were younger. Neither maternal BMI nor eating disorder symptoms significantly predicted authoritative parenting, nor did the addition of the EDI-2 total score make a significant $\mathrm{R}^{2}$ change to the overall regression model.

Authoritarian parenting style was significantly predicted by child age in Step 1 and by child age and EDI-2 total in Step 2. When controlling for child age, mothers were more authoritarian when they reported higher levels of eating disorder symptoms. The addition of maternal eating disorder symptoms made a significant $\mathrm{R}^{2}$ change to the overall model. Maternal BMI was not significantly involved in either step of the model.

Permissive parenting was not predicted by child age or maternal BMI in Step 1 but was significantly predicted by EDI-2 total in Step 2 and the addition of eating disorder symptoms made a significant $\mathrm{R}^{2}$ change to the overall model.

\section{Discussion}


This study examined associations between eating disorder symptoms and parenting style. Greater reports of eating disorder symptoms in this non-clinical sample were related to less adaptive parenting styles, supporting the study's hypotheses.

The first order correlations showed that higher levels of reported drive for thinness were related to more authoritarian and to more permissive parenting styles. Symptoms of bulimia were associated with a more authoritarian parenting style and body dissatisfaction was related to a permissive parenting style. In the regression analyses, the composite measure of eating disorder symptoms was also shown to still be significantly related to authoritarian and permissive parenting styles, even after controlling for the potential effects of child age and maternal BMI. These two parenting styles have previously been shown to be less than optimal (Baumrind, 1971; Darling \& Steinberg, 1993) and this study has now linked them to the presence of eating disorder symptoms. That eating disorder symptoms were positively related to parenting styles which are typically both more (authoritarian) and less (permissive) controlling is in accordance with the notion that eating disorder symptoms may manifest differently for individuals and supports literature which has found mothers with eating psychopathology to be both more controlling (Stein et al., 1994; Tiggemann \& Lowes, 2002), but also to withdraw from stressful eating interactions with their children (Waugh \& Bulik, 1999). These findings provide preliminary evidence to suggest that not only are eating interactions between mothers with symptoms of eating disorders and their children impaired (Stein et al., 1994; Tiggemann \& Lowes, 2002; Waugh \& Bulik, 1999), but that more general parenting might be related to the presence of eating disorder symptoms in non-clinical individuals. However, as these data are cross-sectional, causality cannot be inferred. Further work is needed to investigate the association between parenting and eating disorder symptoms because other variables, such as rigidity of thinking, or co-morbid psychopathology (e.g., high levels of anxiety, depression or obsessive-compulsive symptoms), may be involved in this relationship. 
There were no significant associations between an authoritative parenting style and eating disorder symptoms nor did eating disorder symptoms significantly add to the regression model for authoritative parenting. This suggests that more adaptive parenting is not related to symptoms of eating disorders, which is in accordance with literature which has found more favourable parenting to be related to lower levels of other mental health symptoms (e.g., Leinonen, Solantaus \& Punamäki, 2003).

Limitations of this study include its reliance on self-reported data, the non-clinical sample and the fact that fathers were not included. Future studies should build on these findings by including clinical as well as non-clinical groups of mothers and fathers. Consideration of a broader demographic range of parents with older and younger children is also suggested given the finding that child age was related to parenting style in this group.

This study has shown preliminary evidence to suggest that the presence of eating disorder symptoms in a non-clinical sample of mothers can be related to less than optimal parenting styles. Higher levels of eating disorder symptoms were related to more authoritarian and permissive parenting styles. This study highlights the value of carrying out research into sub-clinical eating disorders as it suggests that even modest levels of eating disorder symptoms can be related to less adaptive styles of parenting. 


\section{References}

Agras, S., Hammer, L. \& McNicholas, F. (1999). A prospective study of the influences of eating-disordered mothers on their children. International Journal of Eating Disorders, $25,253-262$.

Baumrind, D. (1971). Current patterns of parental authority. Developmental Psychology Monograph, Part 2, 4, 1, 1-103.

Berman, K., Lam, R.W. \& Goldner, E.M. (1993). Eating attitudes in seasonal affective disorder and bulimia nervosa. Journal of Affective Disorders, 29, 219-225.

Blissett, J. \& Haycraft, E. (2008). Are parenting style and controlling feeding practices related? Appetite, 50, 477-485.

Blissett, J., Meyer, C. \& Haycraft, E. (2006). Maternal and paternal controlling feeding practices with male and female children. Appetite, 47, 2, 212-219.

Bryant-Waugh, R., Turner, H., East, P. \& Gamble, C. (2007a). Developing a parenting skillsand-support intervention for mothers with eating disorders and pre-school children part 1: Qualitative investigation of issues to include. European Eating Disorders Review, 15, $350-356$.

Bryant-Waugh, R., Turner, H., Jones, C. \& Gamble, C. (2007b). Developing a parenting skills-and-support intervention for mothers with eating disorders and pre-school children: part 2. Piloting a group intervention. European Eating Disorders Review, 15, 439-448.

Child Growth Foundation. (1996). Cross sectional stature and weight reference curves for the $U K$. London, United Kingdom: Child Growth Foundation.

Darling, N. \& Steinberg, L. (1993). Parenting style as context: An integrative model. Psychological Bulletin, 113, 487-496.

Garner, D.M. (1991). Eating Disorders Inventory 2: Professional manual. Odessa, FL: Psychological Assessment Resources. 
Leinonen, J.A., Solantaus, T.S. \& Punamäki, R.L. (2003). Parental mental health and children's adjustment: The quality of marital interaction and parenting as mediating factors. Journal of Child Psychology and Psychiatry, 44, 2, 227-241.

Mazzeo, S.E., Zucker, N.L., Gerke, C.K., Mitchell, K.S. \& Bulik, C.M. (2005). Parenting concerns of women with histories of eating disorders. International Journal of Eating Disorders, 37, S77-S79.

McNicholas, F. (1996). Eating psychopathology and its effect on pregnancy, infant growth and development. Irish Journal of Psychological Medicine, 13, 2, 67-69.

Office for National Statistics. (2005). The National Statistics Socio-Economic Classification user manual <http://www.statistics.gov.uk/methods_quality/ns_sec>.

Robinson, C.C., Mandleco, B., Olsen, S.F. \& Hart, C.H. (2001). The Parenting Styles and Dimensions Questionnaire (PSQD). In: B.F. Perlmutter, J. Touliatos, \& G.W. Holden (Eds.), Handbook of family measurement techniques: Vol. 3. Instruments \& index (pp. 319-321). Thousand Oaks: Sage.

Stein, A., Woolley, H., Cooper, S.D. \& Fairburn, C.G. (1994). An observational study of mothers with eating disorders and their infants. Journal of Child Psychology and Psychiatry, 35, 733-748.

Stein, A., Woolley, H. \& McPherson, K. (1999). Conflict between mothers with eating disorders and their infants during mealtimes. British Journal of Psychiatry, 175, 455461.

Stein, A., Woolley, H., Murray, L., Cooper, P.J., Cooper, S., Noble, F., et al. (2001). Influence of psychiatric disorder on the controlling behaviour of mothers with 1-yearold infants: A study of women with maternal eating disorder, postnatal depression and a healthy comparison group. British Journal of Psychiatry, 179, 157-162.

Tiggemann, M. \& Lowes, J. (2002). Predictors of maternal control over children's eating behaviour. Appetite, 39, 1-7. 
Waugh, E. \& Bulik, C.M. (1999). Offspring of mothers with eating disorders. International Journal of Eating Disorders, 25, 123-133.

Woodside, D.B. \& Shekter-Wolfson, C.F. (1990). Parenting by patients with anorexia nervosa and bulimia nervosa. International Journal of Eating Disorders, 9, 303-309. 
Table I: Pearson's correlations between eating disorder symptoms (EDI-2), parenting style $(P S D Q)$ and maternal and child BMI $(N=105)$

EDI-2 PSDQ

Drive for

Child

thinness Bulimia Body Dis A'tative A'tarian Permis BMI-Z

Bulimia $.593^{* * *}$

Body

dissatisfaction

$.655^{* * *} \quad .605^{* * *}$

Authoritative $\quad-.011 \quad-.145 \quad-.162$

Authoritarian $.277^{* *} \quad .284^{* *} \quad .188 \quad-.450^{* * *}$

Permissive $\quad .258^{* *} \quad .178 \quad .322^{* * *} \quad-.309^{* * *} \quad .454^{* * *}$

Child BMI Z-

scores $^{\dagger}$

$\begin{array}{llllll}-.005 & -.016 & -.027 & .175 & -.240 & -.072\end{array}$

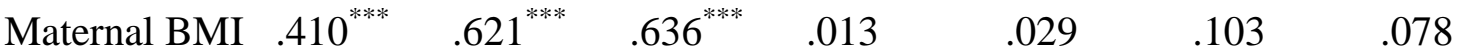

${ }^{* *} \mathrm{p} \leq .01 ; * * * \mathrm{p} \leq .001 \quad\left(\mathrm{p}\right.$-values are two-tailed) ${ }^{\dagger} \mathrm{n}=56$

Body Dis: Body Dissatisfaction; A'tative = Authoritative; A'tarian = Authoritarian; Permis

= Permissive; Child BMI-Z = Child BMI Z-scores 
Table II: Regressions examining the contribution of eating disorder symptoms to parenting styles after controlling for child age and maternal BMI $(N=105)$

\begin{tabular}{|c|c|c|c|c|c|}
\hline & $\mathrm{R}^{2}$ change & $\mathrm{df}$ & Beta & B & SE of B \\
\hline Authoritative: Step 2 & .025 & 1,96 & & & \\
\hline Child age & & & -.253 & $-.011 *$ & .004 \\
\hline Maternal BMI & & & .152 & .017 & .014 \\
\hline EDI-total & & & -.206 & -.008 & .005 \\
\hline Authoritarian: Step 2 & $.083 * *$ & 1,96 & & & \\
\hline Child age & & & .365 & $.015 * * *$ & .004 \\
\hline Maternal BMI & & & -.221 & -.023 & .012 \\
\hline EDI-total & & & .376 & $.013 * *$ & .004 \\
\hline Permissive: Step 2 & $.098 * *$ & 1,96 & & & \\
\hline Child age & & & .069 & .004 & .006 \\
\hline Maternal BMI & & & -.164 & -.025 & .019 \\
\hline EDI-total & & & .408 & $.021 * *$ & .006 \\
\hline
\end{tabular}

${ }^{*} \mathrm{p} \leq .05 ; * * \mathrm{p} \leq .01 ; * * * \mathrm{p} \leq .001$. Note: For brevity, only Step 2 of the regression models is shown. 